\title{
Homens, animais e jaulas: apontamentos para uma zoopoética
}

\section{Márcia Seabra Neves \\ Universidade Nova de Lisboa}

Resumo: Inscrevendo-se no coração da cidade moderna como espaço de (re)encontro do homem com os animais e uma natureza cada vez mais distante, o zoológico institui-se, na realidade, como um espaço artificial de marginalização e confinamento animal, reforçado as fronteiras entre o humano e o não-humano. Pretendese pois, neste trabalho, indagar o modo como esse encontro entre o homem e o animal - através da jaula - é representado no texto literário, espaço privilegiado de apreensão da animalidade, porquanto nele o escritor tenta fixar, pela palavra articulada, a subjetividade dos animais, entrar, pelos poderes da ficção, na sua pele, imaginar o que eles diriam se falassem, conjeturar acerca dos seus saberes sobre o mundo e figurar a sua humanidade. Tomaremos como corpus de análise o conto "O búfalo" de Clarice Lispector (Laços de Família, 1960) e a série "Zôo" de João Guimarães Rosa (Ave Palavra, 1970), interpretados à luz das reflexões teóricas de autores como Gilles Deleuze, Jacques Derrida e John Berger.

Palavras-chave: Jardim zoológico, homens, animais, jaulas, zoopoética

\begin{abstract}
Situated at heart of the modern city and intended to encourage the reunion of man with animals and with an ever more distant nature, the zoo is, in reality, an artificial space for animal segregation and confinement, reinforcing the divide between human and non-human. In this article, we seek to inquire the ways in which this reunion between man and animal (made possible through the cage) is represented in the literary text, a space allowing the apprehension of animality. Writers attempt to use the powers of fiction to put themselves in the place of animals, imagining what they would say if they could talk, speculating about


their knowledge of the world and assessing their human quality. We will focus on the close reading of a short story by Clarice Lispector («The Buffallo» included in the collection Family Ties), as well as the series entitled «Zoo» by João Guimarães Rosa (taken from Ave Palavra, 1970). These texts will be analysed in the light of the theoretical reflection developed by authors such as Gilles Deleuze, Jacques Derrida, and John Berger.

Keywords: Zoo, men, animals, cages, zoopoetics

A coexistência entre o animal e o humano perde-se na noite dos tempos e foi no confronto com o animal, aquele outro tão próximo e ao mesmo tempo tão distante de nós, que o homem desde sempre forjou a sua identidade. No entanto, a crença do sujeito moderno no progresso e no saber científico, aliada a um irrefreável movimento de industrialização e urbanização da sociedade, levou-o a uma explicação do cosmos pelo domínio absoluto da natureza, afastando-o cada vez mais da sua existência natural e do contacto com a vida imediata do animal.

É neste contexto de modernização que surgem os zoológicos, espaços alegóricos em que o homem pode (re)encontrar o animal e uma natureza enigmática ou cada vez mais distante. Paradoxalmente, neste microcosmos do mundo natural, encaixado no espaço urbano, os animais surgem subtraídos da sua verdadeira essência e convertidos em objetos vivos musealizados, compondo uma paisagem artificial para os olhos de quem os observa. 0 texto literário surge, então, como espaço privilegiado para a figuração desse olhar cruzado entre o humano e o não-humano - através da jaula -, porquanto nele o escritor tenta fixar, pela palavra articulada, a subjetividade dos animais, entrar, pelos poderes da ficção, na sua pele, imaginar o que eles diriam se falassem e conjeturar acerca dos seus saberes sobre o mundo.

João Guimarães Rosa e Clarice Lispector foram dois escritores que fundaram, nas respetivas obras, verdadeiras poéticas do olhar - um olhar recíproco e não antropocêntrico - ancoradas no espaço simbólico-ideológico do jardim zoológico. 
1. Num instigante ensaio intitulado "Why look at animals", John Berger afirma que o nascimento dos zoológicos modernos coincide com o início de uma época em que os animais começavam a abandonar o regime de quotidianidade e proximidade com o humano, assinalando assim o epitáfio de uma relação tão antiga quanto o próprio homem. 0 autor explica que, se até ao século XIX, os animais faziam parte integrante da vida quotidiana do homem, iniciou-se desde então um processo de rutura irreversível da longa tradição das relações entre o homem e a natureza, agravado pelo capitalismo corporativo que dominou todo o século XX (Berger 1991: 21).

É então que se ergue, no coração da cidade moderna, o zoológico com o propósito socioeducativo de instrução e edificação públicas, proporcionando a possibilidade de (re)encontro do homem com os animais e com um tempo extinto em relação ao tempo urbano. Ora, segundo Berger, esse espaço urbano, onde as pessoas vão para se encontrarem com os animais e observá-los através das grades, institui-se, na realidade, como uma espécie de monumento vivo à impossibilidade desse encontro, na medida em que a imagem dos animais com que os visitantes se deparam não corresponde à realidade. Não são, pois, animais verdadeiros os que se contemplam no zoológico, mas antes coleções de bichos deslocados da sua natureza intrínseca e debilitados pela clausura e solidão. Com efeito, arrancados do seu habitat natural e expostos à curiosidade alheia, os animais são exibidos como peças de uma exposição e observados por "passantes que fazem do voyeurismo uma forma de entretenimento" (Maciel 2008: 55), deslocando-se pelo zoológico como por uma galeria de arte, funcionando cada jaula como um quadro. Nas palavras de Berger:

A zoo is a place where as many species and varieties of animal as possible are collected in order that they can be seen, observed, studieid. In principle, each cage is a frame round the animal inside it. Visitors visit the zoo to look at animals. They proceed from cage to cage, not unlike visitors in an art gallery who stop in front of one painting, and then move on to the next or the one after next. Yet in the zoo the view is always wrong. Like an image out of focus. (Berger 1991 : 23)

Essa imagem surge desfocada, porque nos encontramos perante criaturas radicalmente alienadas que, isoladas umas das outras e reduzidas a objetos vivos de 
contemplação, compõem uma paisagem artificial, organizada pela ação humana (idem: 2324). Estes espaços de reclusão forçada e confinamento animal caucionam a primazia do humano e a sua dominação sobre a natureza, reforçando as fronteiras entre o homem e o animal, estabelecidas pelo antropocentrismo egocêntrico da máquina antropológica ocidental.

Neste sentido, enquanto zona de contacto entre o humano e os animais anexada ao espaço urbano, o jardim zoológico só pode dececionar, na medida em que o visitante olha, mas nunca chega a encontrar o olhar dos animais que, expropriados da sua ontologia, se tornam seres completamente alheados, adotando uma atitude tipicamente humana, que é a indiferença. A este propósito, John Berger explica que "at the most, the animal's gaze flickers and passes on. They lookside ways. They look blindly beyond" (idem: 28).

Não havendo essa possibilidade de um olhar cruzado entre o homem e o animal, tão próximo e ao mesmo tempo tão distante dos olhos que os observam, fica também inviabilizado o encontro efetivo entre ambas as espécies. É, precisamente, o que sustenta o Jacques Derrida, no seu célebre ensaio "O animal que logo sou". Partindo da experiência de se ter encontrado completamente nu perante o olhar de um gato, o filósofo francês desenvolve uma longa reflexão sobre os limites entre o homem e o animal, não o animal metaforizado e interpretado a partir de uma visão antropocêntrica, mas sim o animal real, aquele outro que existe em face de nós e que pode vir ao nosso encontro. Sentir-se observado, em toda a sua nudez e fragilidade, pelo olhar silencioso e perscrutador de um animal confrontou o pensador com o limite abissal do homem, a fronteira que ele terá que transpor para chegar ao animal (Derrida 1999: 253).

Neste sentido, Derrida distingue dois tipos de aproximação ao animal: a dos que nunca cruzaram o olhar de um animal, fazendo dele uma coisa vista e que não vê, um todo genérico; e a daqueles que, como o próprio Derrida e também John Berger, se fundamentam na troca de olhares com o animal, ou seja, aqueles que consentem o olhar do animal sobre eles tendo em conta o seu ponto de vista, concedendo-lhes o estatuto de sujeito e uma subjetividade própria (idem: 264-265). São, no fundo, todos aqueles que se mostram 
recetivos a uma diluição de fronteiras entre ambas as espécies e reivindicam um logos e um pathos do animal.

Perante estas considerações, o jardim zoológico afigura-se-nos como um espaço obsoleto de confinamento e subjugação dos animais, onde o humano nunca poderá cruzar o olhar de um animal, nem sentir-se observado por ele. Nestes termos, se Derrida tivesse que responder à questão de Berger - "porquê olhar os animais?" - dir-lhe-ia, provavelmente, que é porque eles também nos olham.

No fundo, tanto Derrida como Berger apelam para a necessidade de repensar a forma como olhamos os animais, admitindo que eles não são apenas objetos do nosso voyeurismo prepotente, mas que também nos olham e possuem um mundo específico, não forçosamente mais pobre do que o do humano. 0 filósofo franco-argelino sublinha ainda que esse encontro com a outridade animal só é possível por via da poesia, espaço ficcional por excelência apto à compreensão e aproximação da outridade animal, já que através do fingimento poético, o escritor se liberta da sua natureza humana e trespassa o limite da sua humanidade, para se alojar num corpo animal, sem passar pelo plano metafórico ou imitativo.

É precisamente o que fazem Guimarães Rosa e Clarice Lispector nas suas ficções sobre o zoológico, onde predomina uma apreensão da animalidade bem diferente da dos visitantes dos zoológicos reais.

2. Na sua famosa entrevista a Günter Lorenz, Guimarães Rosa faz a seguinte revelação: "Quando escrevo, descubro sempre um novo pedaço de infinito. Vivo no infinito; o momento não conta" (Lorenz 1965). Visitante assíduo e apaixonado de zoológicos, talvez fosse em busca deste pedaço de infinito que Guimarães Rosa ia escrevendo o que lhe iam dizendo os animais que contemplava nas suas visitas aos zoológicos do mundo.

Esses escritos avulsos encontram-se reunidos no livro póstumo Ave, palavra (1970), numa série de seis capítulos intitulados “Zôo”, cada um deles dedicado a um zoológico visitado pelo autor: o Whipsnade Park de Londres, o zoológico do Rio de Janeiro, o 
Hagenbecks Tierpark de Hamburgo-Stellingen (3ํㅜ e 4o capítulos), o Jardin des Plantes de Paris e o Parc Zoologique du Bois de Vincennes.

Os capítulos são compostos por um conjunto híbrido de breves anotações que traduzem as impressões poético-afetivas registadas pelo narrador durante as suas tentativas de apreensão da outridade animal. Cada anotação corresponde a uma espécie de descrição poética dos animais, polarizada no olhar minucioso do narrador e num exercício criativo de observação que sonda a vida íntima dos seres observados, procurando deles extrair uma linguagem. Com efeito, o autor constrói os seus fragmentos descritivos a partir de um entrelaçamento entre escrita e olhar, traduzindo por palavras as características essenciais dos animais, intimamente relacionadas com as imagens sensoriais recolhidas pelo poeta-prosador no âmago da sua contemplação imaginativa. Esta modelização do referente (animal) pelo signo (palavra) faz-se por meio de engenhosos jogos de palavras, imagens e formas que resultam numa linguagem tão original e complexa quanto o olhar recriador e imaginativo do próprio autor. Eis apenas alguns exemplos das insólitas descrições de Guimarães Rosa:

Um leão ruge a plenos trovões. (Rosa 1985: 67)

A serpente é solipsista, escorreita perfeita, no sem murmúrio movimento, desendireitada, pronta: como a linha enfiada na agulha. (idem: 68)

A cigarra cheia de ci. (idem: 96)

Onça - tanta coisa dura entre boca e olhos. (idem: 97)

A cobra movimenta-se: destra, sinistra, destra, sinistra... /A jibóia, macia, métrica, meandrosa. (idem: 97)

As gazelas assustadas alinham-se flexilfacilmente. (idem: 192)

O mangusto, só a diminutivos. Eis: um coisinho, bibichinho ruivo, ratote, minusculim, que assoma por entre as finas grades a cabecinha, truangular. Mimo de azouhue, todo pessoa e curiodidade, forte pingo de vida. Segura as grades, empunha-as, com os bracinhos para trás e o peito ostentado, num desabuso de prisioneiro veterano. Mas enfeitaram-lhe o pescoço com uma fitinha azul, que parece agradar-lhe mais que muitíssimo." (idem: 21)

Na realidade, Rosa reinventa os animais enjaulados a partir da linguagem, no intuito 
de lhes conceder, no não-lugar da escrita, outra possibilidade zoo-existencial, fora do domínio antropocêntrico e das grades do zoológico. Entende-se, assim, o título da coletânea em que se inserem estes textos - Ave, palavra -, que pode ser entendido como uma saudação (do latim ave) à palavra e aos animais por ela traduzidos e recriados, graças ao voo (ave, pássaro) da imaginação, ou ainda como reivindicação da palavra para aqueles que a não têm e que, por isso mesmo, sempre foram relegados para a base da pirâmide, na tradicional hierarquia das espécies animais (humano e não-humano).

Guimarães Rosa cria, assim, uma espécie de filosofia - ou, talvez melhor, filozoofia da linguagem que consiste em escrever e pensar como se fosse o outro animal, adentrandose no corpo dos bichos para decifrar a sua presumível vida interior e contruir minuciosos retratos psicológicos desses entes não-humanos. Por outras palavras, o autor "desconstrói o saber hegemónico dos humanos e encarna[-se] na voz dos animais" (Souza 2011: 84). Um dos exemplos mais paradigmáticos desta desterritorialização do humano em direção à animalidade são as notas que relatam a terrível angústia de um ratinho branco despejado na jaula de uma cascavel e prestes a ser devorado. A cena foi observada no Jardin des Plantes:

Uma cascavel, nas encolhas. Sua massa infame.

Crime: prenderam, na gaiola da cascavel, um ratinho branco. 0 pobrinho se comprime num dos cantos do alto da parede da tela, no lugar mais longe que pôde. Olha para fora, transido, arrepiado, não ousando choramingar. Periodicamente, treme. A cobra ainda dorme. (Rosa 1985: 215)

Nesta passagem, o escritor deixa-se contagiar pelas emoções do ratinho, comparticipa da sua aflição e incorpora a sua visão do mundo, transpondo para o corpo das palavras todo o seu pavor e frustração perante a morte inevitável. 0 autor reivindica, deste modo, um logos e um pathos no animal, ou seja, uma consciência e sensibilidade à dor e ao sofrimento tão legítimas como as que assistem ao humano, colocando em questão o humanismo logocêntrico fundado na racionalidade e na linguagem humana como atributos justificativos do primado do homem sobre o reino animal. 
Ora, esta exploração da subjetividade animal comprova a compaixão e cumplicidade de Guimarães Rosa em relação aos animais que descreve, mas também o seu compromisso ético para com eles, expressamente evocado pela máxima que abre o terceiro "Zôo" de Ave, palavra (Hamburgo - Stellingen): "Pórtico: Amar os animais é aprendizado da humanidade" (Rosa 1985: 120). Neste ponto, o pensamento zooético de Guimarães Rosa antecipa o do escritor sul-africano J. M. Coetzee que, já em finais do século XX afirmará, no seu romanceensaio As vidas dos animais (1999) e através da personagem Elizabeth Costello, que: “Quem afirma que a vida importa menos aos animais do que a nós nunca teve nas suas mãos um animal a lutar pela vida. Todo o ser do animal se lança nessa luta, sem reservas. (...) todo o seu ser se encontra na sua carne viva" (Coetzee 2000: 72).

Na verdade, Guimarães Rosa não só restabelece, pelos poderes da ficção, o pacto perdido entre o homem e o animal - nomeadamente através de uma reiterada e sugestiva comparação entre o homem e o macaco: "O macaco: homem desregulado. 0 homem: viceversa; ou idem.” (Rosa 1985: 124) -, como também questiona a condição existencial do homem, como se pode comprovar pelo enigmático quesito: "Se todo o animal inspira sempre ternura, o que houve, então, com o homem?" (idem: 122). Paralelamente, e em sentido contrário, a uma (re)valorização ética e afetiva do animal, o narrador contrapõe uma visão negativa da humanidade e do ser humano, desprovido de ternura e movido por uma impiedade utilitarista que o impele a uma coisificação da natureza, dos animais e dele próprio.

Assim, as lições de Guimarães Rosa apreendidas no âmago da observação e da força intuitiva do olhar apelam a uma reconfiguração, por via dos afetos, da cartografia humanoanimal e à defesa de um continuum ontológico entre ambas as espécies.

3. Outra escritora que elege o jardim zoológico como cenário para a encenação ficcional do encontro entre o animal e o humano é Clarice Lispector. Tal como em Guimarães Rosa, esse encontro também se faz por via do olhar, só que, no zoológico de Clarice, o humano não é o único observador, porquanto ele não se desloca lá apenas para observar os animais 
enjaulados, mas sobretudo para ser observado por eles e se descobrir através desse olhar misterioso e indagativo.

O conto "O búfalo", 1 inserto na coletânea Laços de Família (1960), é um dos exemplos mais notáveis dessa troca de olhares entre o homem e o animal, através das grades. Tratase da história de uma mulher - "a mulher do casaco marrom" (Lispector 1983: 147) - que, devastada por uma deceção amorosa, vai ao jardim zoológico com o propósito de "aprender a odiar para não morrer de amor" (idem: 153). Corroída pela amargura da rejeição, a protagonista acredita que esse "ponto de ódio" (idem: 147) que procura se encontra nos olhos das feras enjauladas. No entanto, era primavera e, contrariamente às suas expectativas, o jardim zoológico estava em festa e tudo em seu redor, em vez de ódio e violência, lhe despertava um sentimento insuportável de amor e compaixão, desde os eflúvios de prazer dos leões, à felicidade dos macacos, passando pela inocência da girafa, a humildade do hipopótamo, a bondade do elefante ou ainda a paciência do camelo.

$\mathrm{Na}$ sua angustiante deambulação por entre as jaulas do zoológico, a mulher sem nome, que procura no olhar dos animais uma via de acesso a uma zona obscura de si mesma, acaba por se irmanar com eles, descobrindo-se tão aprisionada quanto aqueles seres caçados, arrancados dos seus espaços, encarcerados e domesticados. Essa revelação fez-se no silencioso e perscrutante encontro com o quati:

De dentro da jaula o quati olhou-a. Ela o olhou. Nenhuma palavra trocada. Nunca poderia odiar o quati, que no silêncio de um corpo indagante a olhava. Perturbada, desviou os olhos da ingenuidade do quati. (...) A testa estava tão encostada às grades que por um instante lhe pareceu que ela estava enjaulada e que um quati livre a examinava. (idem: 152)

Neste jogo de olhares, a jaula torna-se um espelho da sua própria condição e a mulher descobre-se prisioneira de si mesma, por uma educação que nunca a ensinara a odiar. Por isso é que "só sabia resignar-se, que só sabia suportar, só sabia pedir perdão, só sabia perdoar, que só aprendera a ter a doçura da infelicidade, e só aprendera a amar, a amar, a amar" (idem: 153). Assim, a mulher sai da selva urbana, liberta-se dos muros da cidade, e vem procurar no espaço do zoológico, nas jaulas das feras selvagens, uma nova 
energia para (sobre)viver, um estímulo para a libertação das suas forças instintivas, das suas pulsões reprimidas pela cultura.

Ora, esse retorno a um estado primitivo do ser, encontra-o finalmente no olhar de um búfalo negro. A aproximação entre ambos fez-se de modo gradual. Cansada e desanimada, já nos limites do seu "desespero implorante" (idem: 154), a mulher avista ao longe um búfalo que se destaca pela sua masculinidade. Todos os seus sentidos femininos se despertam ao sentir-se observada, ainda que por breves instantes, pelo imponente macho:

De longe, no seu calmo passeio, o búfalo negro olhou-a um instante. (...) E mais uma vez o búfalo pareceu notá-la. Como se ela não tivesse suportado sentir o que sentira, desviou subitamente o rosto e olhou uma árvore. Seu coração não bateu no peito, o coração batia oco entre o estômago e os intestinos. (idem: 155)

A mulher que fora ao zoológico em busca de ódio acabará por, paradoxalmente, encontrar no búfalo a violência do amor, perdendo-se numa entorpecedora indecibilidade de sentimentos. Tal como acontecera com Derrida e o seu gato, sentir-se observada, em toda a sua fragilidade, pelo olhar do búfalo, conduz a mulher ao limite abissal do humano, colocando-a em situação de vertigem (Derrida 1999: 253). Com efeito, sob o olhar do animal, que a penetra no mais íntimo do seu corpo e alma, a mulher transforma-se: uma "coisa branca" (idem: 156) e "viscosa como saliva" (ibidem) espalha-se dentro dela, ao mesmo tempo que também começa a escorrer "um primeiro fio de sangue negro" (ibidem). O búfalo vira-lhe costas, mas ela provoca-o e, como que respondendo aos seus gemidos suplicantes, o animal aproxima-se. É então que ambos se enfrentam num insondável e enigmático duelo de olhares através das grades:

Devagar ele se aproximava. Ela não recuou um só passo. Até que ele chegou às grades e ali parou. Lá estavam o búfalo e a mulher, frente a frente. Ela não olhou a cara, nem a boca, nem os cornos. Olhou seus olhos.

E os olhos do búfalo, os olhos olharam seus olhos. E uma palidez tão funda foi trocada que a mulher se entorpeceu dormente. De pé, em sono profundo. Olhos pequenos e vermelhos a olhavam. Os olhos do 
búfalo. A mulher tonteou surpreendida, lentamente meneava a cabeça. (idem: 157)

$\mathrm{Na}$ intensidade deste encontro inesperado, assiste-se a uma simbiose intercomunicante de naturezas, que se concretiza pela travessia das fronteiras ontológicas entre o animal e o humano. A mulher animaliza-se pela libertação dos seus instintos mais primitivos e o búfalo humaniza-se, ao reagir às pulsões animalescas da mulher. Estabelecese entre ambos uma relação de puro devir, no sentido deleuziano do termo, ou seja, numa intertroca entre humanidade e animalidade, que se traduz pelo fluxo constante entre o humano ou e o não humano e se processa por meio de uma desterritorialização do indivíduo (humano ou não humano) que, só saindo de si próprio, poderá verdadeiramente sentir e pensar a alteridade (Deleuze/Guattari 1980: 291). A mulher e o búfalo invadem o território um do outro, num combate que termina com a queda da mulher para a vertigem, não se sabe se da morte ou do orgasmo:

Inocente, curiosa, entrando cada vez mais fundo dentro daqueles olhos que sem pressa a fitavam, ingénua num suspiro de sono, sem querer nem poder fugir, presa ao mútuo assassinato. Presa como se sua mão se tivesse grudado para sempre ao punhal que ela mesma cravara. Presa, enquanto escorregava enfeitiçada ao longo das grades. Em tão lenta vertigem que antes do corpo baquear macio a mulher viu um céu inteiro e um búfalo. (Lispector 1983: 157-158)

Assim, a experiência ficcional de Clarice Lispector no plano da animalidade não se fica pela superficialidade da analogia, mas impõe uma radical transgressão de fronteiras entre o humano e o não-humano, numa indagação recíproca da condição animal do homem. O jardim zoológico converte-se, assim, num espaço simbólico de descoberta e projeção do sujeito moderno, imerso num regime de sujeição que os animais enjaulados tornam mais tangível e evidente.

Libertar o sujeito (humano e não humano) das grades físicas ou metafísicas que o aprisionam é o que pretendem Clarice Lispector e Guimarães Rosa, através dos seus textos, que instituem verdadeiras poéticas de um olhar cruzado entre o homem e o animal. Em ambos, só a cartografia redentora da palavra permite desenjaular os seus bichos, sejam eles 
humanos ou não-humanos.

\section{NOTA}

${ }^{1}$ Escrito em maio de 1956 e publicado pela primeira vez na Revista Sonhos, na edição de junho de 1960. Nesse mesmo ano, é relançado na coletânea Laços de família.

\section{Bibliografia}

Berger, John (1991), About looking, New-York, Vintage International.

Coetzee, J. M. (2000), As vidas dos animais, Lisboa, Temas e Debates.

Deleuze, Gilles / Guattari, Félix (1980), Capitalisme et schizophrénie. Mille Plateaux, Paris, Les Éditions de Minuit.

Derrida, Jacques (1999), “L'animal que donc je suis (à suivre)”, in Marie-Louise Mallet (coord.), L'animal autobiographique, Paris, Galilée, 251-301.

Lispector, Clarice (1983), Laços de família: contos, Rio de Janeiro, Nova Fronteira. 
Lorenz, Günter (1965), “Diálogo com Guimarães Rosa”. Disponível em :

http://www.elfikurten.com.br/2011/01/dialogo-com-guimaraes-rosa-entrevista.html. Consultado a 26/09/2017.

MACIEL, Maria Esther (2008), O animal escrito - um olhar sobre a zooliteratura contemporânea, São Paulo, Lumme editor.

Rosa, João Guimarães (1985), Ave, Palavra, Rio de Janeiro, Nova fronteira.

Souza, Maria Eneida de (2011), "De animais e de literatura: Rosa, Kafka e Coetzee”, Aletria: Revista de Estudos de Literatura, vol. 21, ㄲo 3, 83-90.

Márcia Seabra Neves, doutorada em Cultura pela Universidade de Aveiro, é investigadora de pós-doutoramento e membro integrado do Instituto de Estudos de Literatura e Tradição da Universidade Nova de Lisboa, onde desenvolve, desde 2012, um projeto de investigação subordinado ao tema "Zooficções: figuras da animalidade nas narrativas portuguesa e brasileira contemporâneas". É também membro integrado do Centro de Línguas, Literaturas e Culturas da Universidade de Aveiro.

Tem vários artigos publicados no âmbito dos estudos culturais, da literatura comparada e da figuração da animalidade na narrativa portuguesa dos séculos XX e XXI. É autora das obras: Da francofilia no imaginário presencista: da NRF à presença, Lisboa, Fundação Calouste Gulbenkian, 2013 (ISBN: 978-972-31-1466-9); Zooficções: figuras da animalidade na narrativa portuguesa contemporânea, Lisboa, IELT - FCSH / NOVA, 2016 (ISBN: 978-98999761-0-8). 